\title{
Research Article \\ Co-Effects of Graphene Oxide and Cement on Geotechnical Properties of Loess
}

\author{
Dongbo Li, ${ }^{1}$ Pengbo Lei $\mathbb{D},{ }^{1}$ Hongchi Zhang, ${ }^{1}$ Jiaping Liu, ${ }^{2}$ and Wei Lu $\mathbb{D}{ }^{1,2}$ \\ ${ }^{1}$ School of Science, Xi'an University of Architecture \& Technology, Xi'an 710055, China \\ ${ }^{2}$ State Key Laboratory of Green Building, Western China, Xi'an 710055, China \\ Correspondence should be addressed to Wei Lu; luwei@xauat.edu.cn
}

Received 12 June 2020; Revised 23 November 2020; Accepted 18 February 2021; Published 11 March 2021

Academic Editor: Peter Majewski

Copyright (c) 2021 Dongbo Li et al. This is an open access article distributed under the Creative Commons Attribution License, which permits unrestricted use, distribution, and reproduction in any medium, provided the original work is properly cited.

Improvement of geotechnical properties of soil by cementitious additives and nanomaterials is commonly used method. However, few systematic research studies on the co-effects of them on the geotechnical properties of loess have been explored. In the present research, the enhancement technique of loess was proposed based on the co-effects of graphene oxide (GO) and cement. In addition, the compactability, mechanical properties, water resistance, and microstructure of the GO/cement/loess ternary system were studied. The results revealed that, with the increase of incorporation of GO $(0.03,0.06,0.09$, and $0.12 \mathrm{wt}$. \%), the optimum moisture decreased, while the dry density, mechanical properties, and water resistance increased significantly. And an optimum GO content of 0.09 wt. \% was determined according to mechanical properties and water resistance. Moreover, the scanning electron microscope (SEM) results revealed that the microstructure was densified and the characteristics of pores were refined. And the co-work mechanisms of GO/cement on loess were summarized. All the results indicated that the GO/cement mixture has remarkable co-effects on the geotechnical properties of loess.

\section{Introduction}

As one of the earliest building materials in human history, raw soil building has been widely used for thousands of years due to its convenience, good thermal performance, and less pollution. To date, there are still billions of raw soil buildings in western China, which is the main loess region. But there is no denying that raw soil material's application is somehow limited because of its low strength, poor durability, and volume stability. Therefore, the improvement of raw soil material is of great significance for the regeneration and development of raw soil structure [1-3].

Aiming at this problem, many studies had been conducted to improve the properties of loess. In the early stage, different kinds of plant fibers such as straws $[4,5]$ and wood [6] were used to enhance the loess, whose positive effect was mainly on the shear strength ductility but not the compressive strength [7]. Later on, various cementitious additives like cement [8], fly ash [9], and lime [10] were incorporated into the soil [11-13], which illustrated a better effect on the durability and mechanical property of soil sample, due to the filling and hydration effects. In recent years, with the rise of nanomaterials, a novel corresponding soil enhanced technique has gained new development direction. At present, nanomaterials such as $\mathrm{SiO}_{2}$ [14], $\mathrm{TiO}_{2}$ [15], and $\mathrm{Al}_{2} \mathrm{O}_{3}$ [16], carbon nanotubes (CNTs) [17], and graphene oxide (GO) [18-26] have been widely used to improve the performances of cement-based materials because of the high strength, high surface activity, small size, and other advantages over conventional materials.

However, the inherent characteristics of soil make it impossible for nanomaterials to react directly with soil [27]. The enhancement of soil by nanomaterials is due to the existence of cementitious additives which can be inspired and promoted by nanomaterials $[28,29]$. Therefore, the enhanced technique of cementitious additives-treated soil by reinforced nanomaterials was proposed. Bahmani et al. used $\mathrm{SiO}_{2}$ nanoparticles and cement-stabilized residual soil to add $0.4 \%$ nanosilicon to the cement-treated soil, and the compressive strength of the soil increased by $85 \%$. Additionally, the experimental results illustrated that the addition of nanomaterials had a noticeable effect on the compaction and 
fluidity of the soil samples [30]. Figueiredo et al. investigated the effects of CNTs on the mechanical properties of soil, which indicated that the compressive strength of soil increased by $77 \%$ based on a good dispersion of CNTs in soil matrix [31].

In particular, the $\mathrm{GO}$ is the rising star of nanomaterials in recent years, which has been commonly used to enhance metals, ceramics, and cement, due to its higher active and better dispersion with the presence of amount of functional oxygen groups on its surface (Figure 1). Nevertheless, in the field of construction, most research works as yet have focused on the cementitious materials reinforced by GO, such as cement paste, mortar, and concrete [18-26], ignoring the research with soil matrix. Up to now, only literature [27] had reported the cement-treated soil enhanced by GO with different incorporations, which showed that the incorporation of GO degraded the compressibility and plasticity, while the compressive strength and shear strength were improved with the increase of GO incorporation. The obtained results indicated that the GO as an enhanced agent had a considerable effect on the cement-treated soil. Although studies about the cement-treated soil enhanced by GO have been on the way, it is obviously still in its infant stage.

So, in the present study, different incorporations of GO was mixed with the cement to enhance loess sample in western China. The enhanced effect of GO/cement on loess was estimated based on the compactability, mechanical properties, water resistance, and microstructure tests. Furthermore, the mechanism of co-effects of GO and cement on the soil matrix was analyzed.

\section{Materials and Methods}

2.1. Raw Materials. The loess utilized in the experiment was collected from Lintong District of Xi'an in western China. Before the experiment, the particle contents, chemical compositions, and physical properties of the studied loess were tested in accordance with the Chinese National Specification (GB/T 50123-2019), as shown in Tables 1-3, respectively. As shown in Table 1, the most content of loess is silt with a proportionality of almost $80 \%$, and then is the clay and the least is sand, which is consistent with the characteristics of loess particle distribution.

The P.O. 42.5 ordinary Portland cement was used in the experiment, which was produced by Tongchuan Dongguan cement Co., Ltd. The chemical compositions are shown in Table 4 . The GO suspension with a solid content of $1.0 \%$ was purchased form Changzhou Sixth Element Materials Technology Co., Ltd. The results of element analysis are shown in Table 5. Ordinary tap water was used to dilute the $\mathrm{GO}$ and make specimens.

2.2. Preparation of Specimens. The mix proportion should be determined firstly to prepare the specimens used in the experiment. The cement content was 15 wt. \% of the loess matrix, while the GO was added with the incorporation of $0.03,0.06,0.09$, and $0.12 \mathrm{wt}$. $\%$ of cement. When it comes to

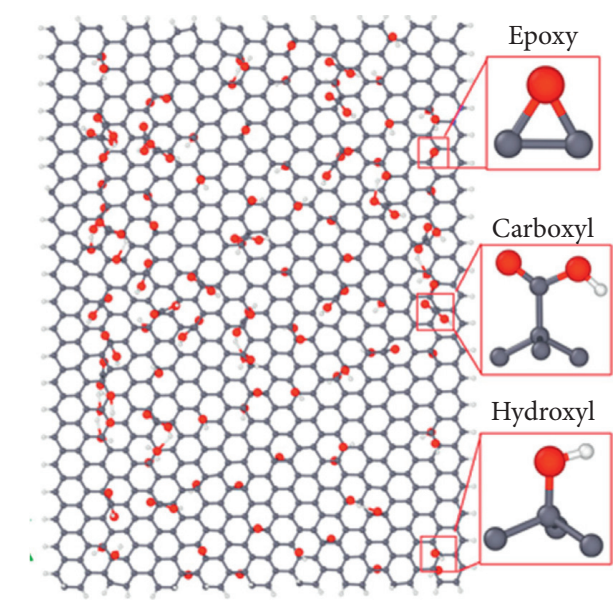

Figure 1: Atomic configuration diagram of GO.

the water content, the water/solid (cement + loess) ratio of 0.4 was chosen.

At the beginning, the GO suspension was diluted to the specified concentration needed in the experiment and then ultrasonicated for 15 minutes to obtain a homogeneous solution (Figure 2). At the same time, the cement and loess were dry mixed with each other for $5 \mathrm{~min}$. Then, the prepared GO suspension was poured into the cement/loess mixture slowly, and then the GO/cement/loess system would be mixed for another $5 \mathrm{~min}$ to obtain homogeneous slurry.

On the basis of the work described above, the fresh slurry would be poured into mold with the dimension of $40 \times 40 \times 160 \mathrm{~mm}$ on time to prepare the specimens needed for experiments of the mechanical property, water resistance, and microstructure. And then, the molds were removed after 24 hours, followed by covering plastic bags on the specimen to prevent water loss too fast and cracking (Figure 3). The composite material was cured for $7 \mathrm{~d}, 14 \mathrm{~d}$, and $28 \mathrm{~d}$, respectively, at room temperature for testes needed.

2.3. Testing Method. According to the Chinese National Standard (GB/T50081-2016), the flexural strength test is carried out by adopting the method of three-point bending at $7 \mathrm{~d}, 14 \mathrm{~d}$, and $28 \mathrm{~d}$, with a displacement control rate of $1.2 \mathrm{~mm} / \mathrm{min}$. For the unconfined compressive strength test, half of the specimens broken in flexural strength test was performed with a rate of $2 \mathrm{~mm} / \mathrm{min}$, by using the special compressive equipment with a contact area of $40 \times 40 \mathrm{~mm}$ (Figure 4). The flexural and compressive strength were calculated as follows:

$$
\begin{gathered}
\sigma_{f}=\frac{3 F l}{2 b d^{2}}, \\
\sigma_{c}=\frac{F}{A},
\end{gathered}
$$

in which $F$ is the applied vertical load, $l$ is the span between supports, $A$ is the cross section of the compressive specimens, and $d$ and $b$ are the depth and width of specimens with both dimensions of $40 \mathrm{~mm}$. 
TABLE 1: Particle contents of the studied loess.

\begin{tabular}{lcc}
\hline Sand $(\%)(0.075 \mathrm{~mm}<$ size $<2 \mathrm{~mm})$ & Silt $(\%)(0.005 \mathrm{~mm}<$ size $<0.075 \mathrm{~mm})$ & Clay $(\%)($ size $<0.005 \mathrm{~mm})$ \\
\hline 1.23 & 79.21 & 19.56 \\
\hline
\end{tabular}

TABLe 2: Chemical compositions of the studied loess.

\begin{tabular}{lcccc}
\hline $\mathrm{SiO}_{2}(\%)$ & $\mathrm{Al}_{2} \mathrm{O}_{3}(\%)$ & $\mathrm{Fe}_{2} \mathrm{O}_{3}(\%)$ & $\mathrm{CaO}(\%)$ & $\mathrm{K}_{2} \mathrm{O}(\%)$ \\
\hline 65.17 & 16.22 & 3.56 & 4.01 & 2.24 \\
\hline
\end{tabular}

Table 3: Physical properties of the studied loess.

\begin{tabular}{lcccc}
\hline Moisture content (\%) & Optimum moisture content (\%) & Liquid limit (LL) (\%) & Plastic limit (PL) (\%) & Plasticity index (PI) (\%) \\
\hline 8.1 & 18.3 & 47.24 & 35.46 & 11.78 \\
\hline
\end{tabular}

TABle 4: Chemical compositions of ordinary Portland cement (wt. \%).

\begin{tabular}{lcccccc}
\hline $\mathrm{SiO}_{2}$ & $\mathrm{Al}_{2} \mathrm{O}_{3}$ & $\mathrm{Fe}_{2} \mathrm{O}_{3}$ & $\mathrm{MnO}_{2}$ & $\mathrm{SO}_{3}$ & $\mathrm{CaO}$ & Ignition loss \\
\hline 22.60 & 4.98 & 2.90 & 2.32 & 2.31 & 61.60 & 4.48 \\
\hline
\end{tabular}

TABLE 5: Element analysis of GO.

\begin{tabular}{lllllcccr}
\hline \multicolumn{4}{c}{ Elemental analysis (wt\%) } & \multicolumn{3}{c}{ Elemental analysis (mol,\%) } \\
$\mathrm{C}$ & $\mathrm{H}$ & $\mathrm{N}$ & $\mathrm{O}$ & $\mathrm{S}$ & $\mathrm{C}$ & $\mathrm{O}$ & $\mathrm{S}$ & Oxygen to carbon molar ratio/mol \\
\hline 46.76 & 2.78 & 0.15 & 43.82 & 1.03 & 58.442 & 41.075 & 0.483 & 0.670 \\
\hline
\end{tabular}

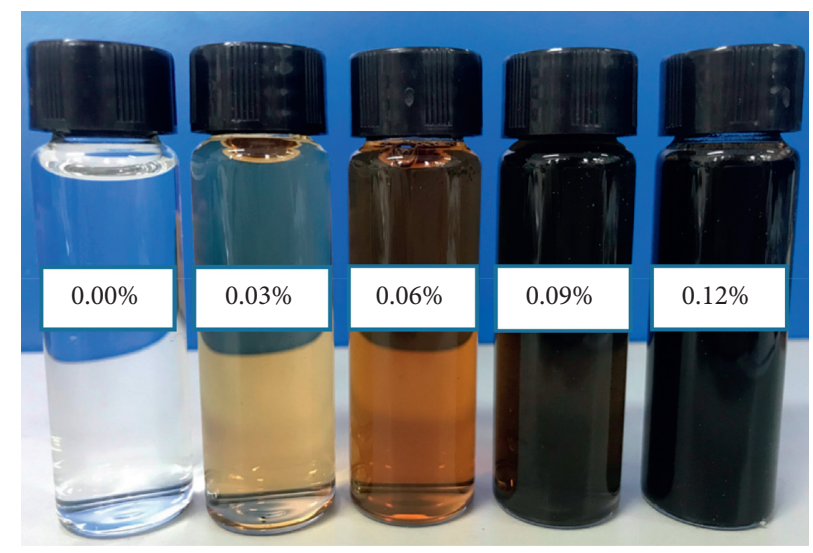

FIgURE 2: GO solution with different concentrations.

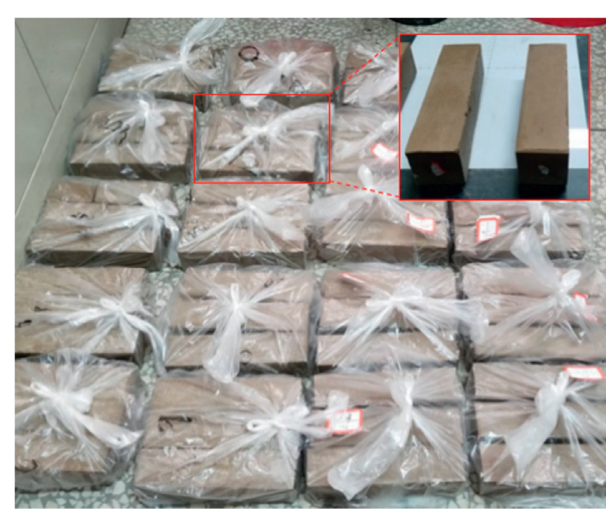

FIGURE 3: Specimens covered by plastic bags. 


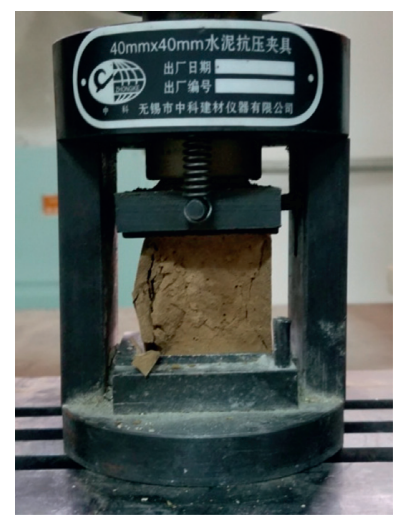

(a)

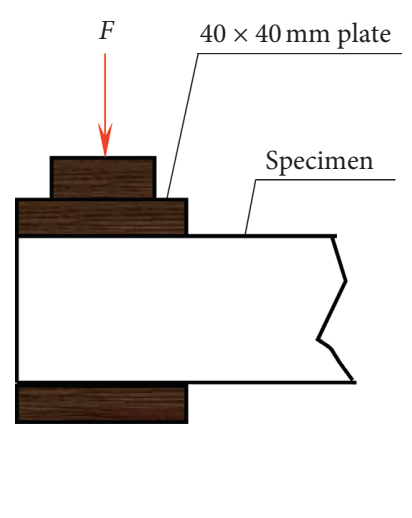

(b)

Figure 4: The compressive test: (a) the figure of front view; (b) the schematic diagram from side view.

According to the Chinese National Standard (GB/T501232019), the optimum moisture content is determined by compaction tests. The loess samples with different water contents are put into the compacted cylinder by dividing into three layers. After each layer being laid, the loess samples are hammered for 25 blows. Finally, the compacted cylinders are filled with the compacted samples. The wet density can be obtained by dividing the total weight of the compacted samples by the volume of the compacted cylinder. Then, the dry density can be further calculated according to the following formula:

$$
\rho_{d}=\frac{\rho_{0}}{1+0.01 \omega},
$$

in which $\rho_{d}$ and $\rho_{0}$ are dry density and wet density, respectively, while $\omega \%$ is the moisture content. According to the method abovementioned, tests of each group with different water contents are conducted, and the relation curves between dry density and moisture content are plotted. Based on the curves, the ordinate of the peak point is the maximum dry density, while the corresponding abscissa is just the optimal moisture content.

To evaluate the water resistance of $\mathrm{GO} /$ cement/loess system, the water adsorption and softening coefficient were tested. For water adsorption test, the dry weight of specimens at $28 \mathrm{~d}$ was weighed firstly, and then the weight after being immersed in water for $1 \mathrm{~d}$ was measured again. The water adsorption was obtained according to the following:

$$
W=\frac{M_{1}-M_{2}}{M_{0}} \times 100 \%,
$$

where $W$ is water absorption (\%), $M_{1}$ is the weight of the specimen after immersion (g), and $M_{0}$ is the dry weight of the specimen (g). For softening coefficient, the compressive strength of specimens at $28 \mathrm{~d}$ was tested, and the corresponding compressive strength of the specimens immersed in water for $1 \mathrm{~d}$ was also tested, and then the softening coefficient was determined according to the following equation:

$$
K=\frac{I_{1}}{I_{0}}
$$

where $K$ is the softening coefficient, $I_{0}$ is the compressive strength at $28 \mathrm{~d}$, and $I_{1}$ is the corresponding compressive strength after immersion in water.
The microstructure of the GO/cement/loess sample was characterized by adopting the FEI Quanta200 scanning electron microscope (SEM) after gold coating.

\section{Results and Discussion}

3.1. Characterization of GO. The GO nanosheets after ultrasonication were characterized by AFM, as shown in Figures 5(a) and 5(b). According to the AFM images, the mean thickness of GO nanosheets is about $1.0 \mathrm{~nm}$, indicating that the thickness has reached the monolayer. Figure 5(c) shows the size distribution curves of the GO, which indicates that the size distribution is approximate normal distribution and the mean lateral dimension is about $5.12 \mu \mathrm{m}$. Figure 5(d) shows the SEM image of GO. In accordance with the image, GO is a wrinkled sheet.

3.2. Effect of GO on the Compactability. Figure 6 presents the dry density and moisture of cemented loess with different incorporations of GO. As shown, the dry density increased with the increasement of GO incorporation in the cemented loess, while the optimum moisture showed a decreasing trend. In more detail, corresponding to the GO content of $0.03,0.06,0.09$, and 0.12 wt. $\%$, the dry density increased by $2.25 \%, 5.62 \%, 7.3 \%$, and $9.55 \%$ compared with the cement/soil without GO, respectively. And the optimum moisture decreased by $1.22 \%, 3.66 \%, 6.1 \%$, and $7.93 \%$, respectively.

The results may be due to the synergistic effect of GO and cement on loess matrix; that is, the microstructure with the presence of C-S-H gel and the interface bonding will be denser. Based on the agreement that the GO can facilitate the hydration process of cement and improve the formation of $\mathrm{C}-\mathrm{S}-\mathrm{H}$ gel, it can be concluded that the pore characteristics of $\mathrm{GO} /$ cement/loess would be improved, resulting in the abovementioned results, which had been also reported by Naseri [27]. In addition, the decease of the optimum moisture content may be attributed to the decrease of the pore characteristics of samples refined by the stronger interconnection between GO, cement, and C-S-H gel. 


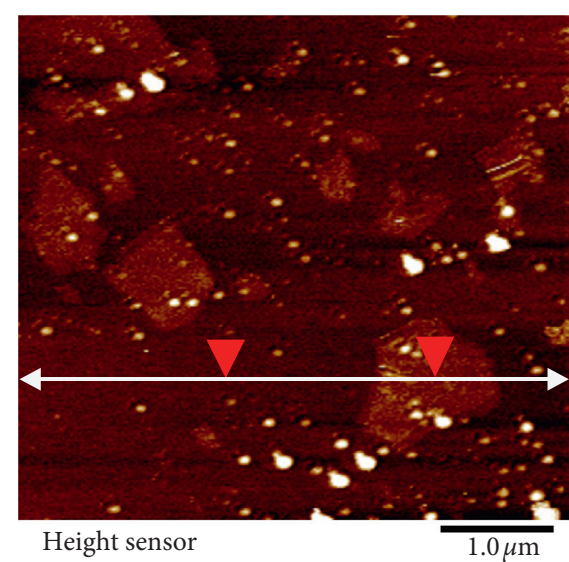

(a)

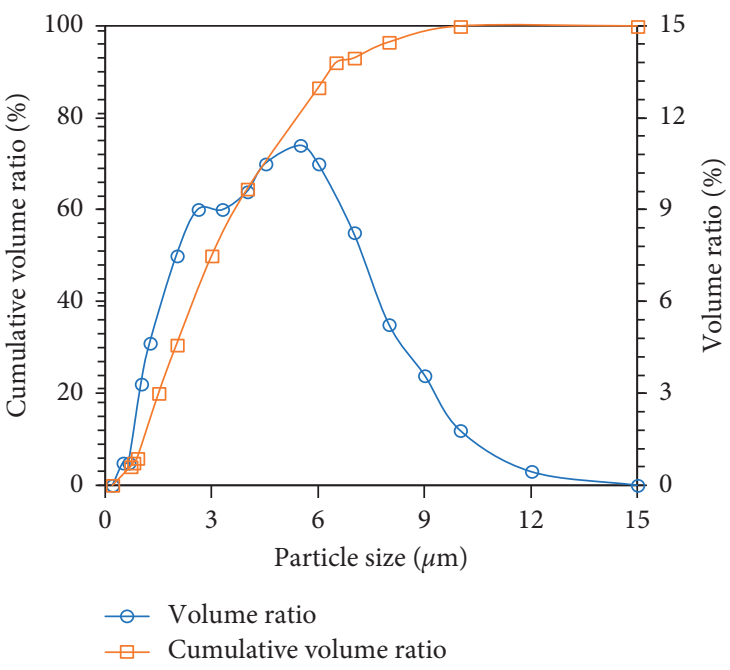

(c)

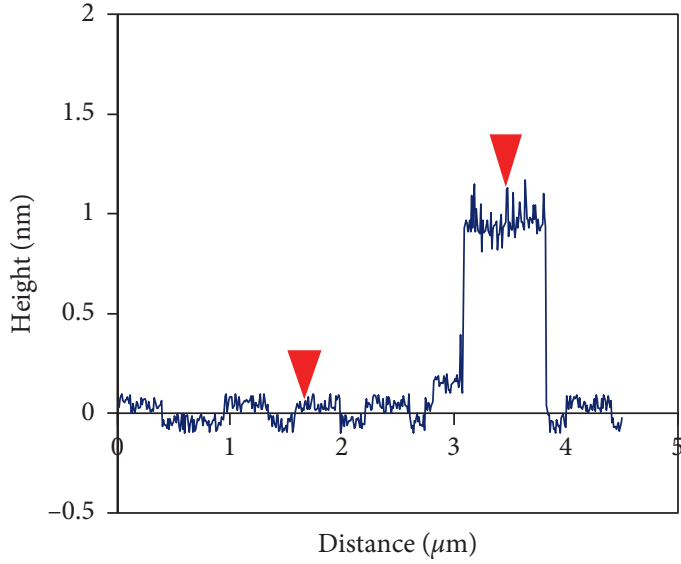

(b)

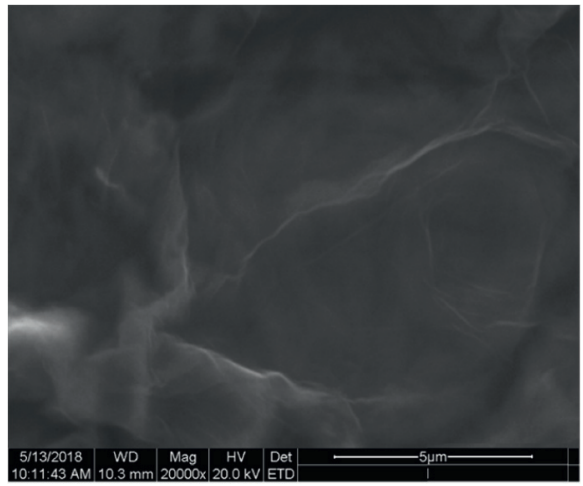

(d)

FIgURE 5: Characterization of GO: (a) AFM image of GO; (b) height profile of GO nanosheet; (c) size distribution curves of GO; (d) SEM image of GO.

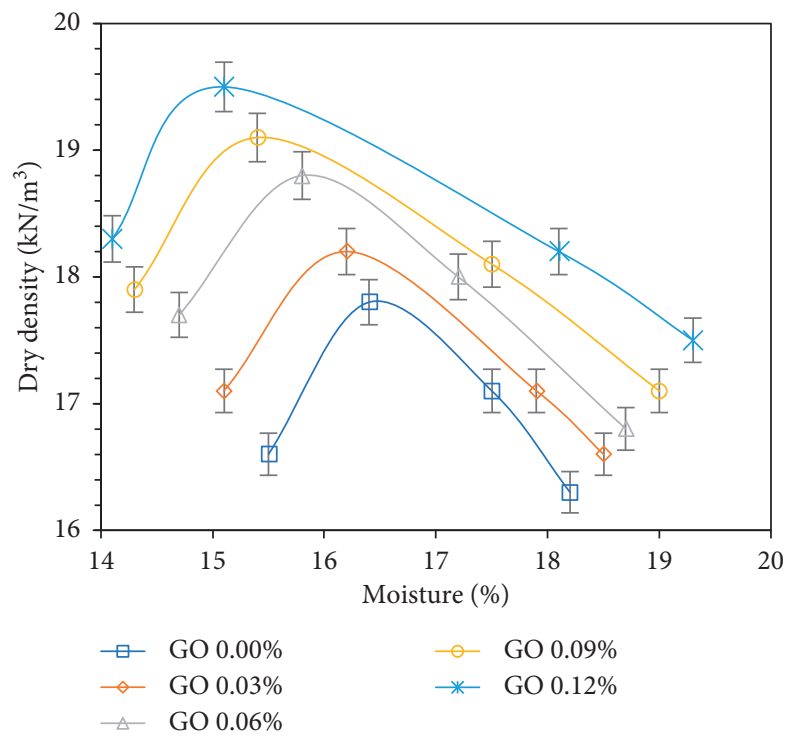

FIGURE 6: Curves of compactability of cemented loess changing with GO incorporation. 
3.3. Effect of GO on the Compressive Stress-Strain Behavior. Figure 7 shows the effect of GO nanosheets on the compressive stress-strain behavior of the soil samples for 7, 14, and $28 \mathrm{~d}$. As observed, the increase of GO concentration led to the increase of stiffness and the decrease of strain. The stiffness of the specimen increased more obviously as the curing time becomes longer.

According to Figure 7, the ultimate strains of the studied cement/loess sample with different GO incorporations are shown in Figure 8(a). Additionally, according to the insets in Figure 7 , for the $0-0.1 \%$ strain stage, the stress is almost proportional to the strain, so we chose the stage as the elastic region; then Young's modulus could be obtained by calculating the secant slope, as shown in Figure 8(b).

As observed in Figure 8(a), the ultimate strain decreased obviously with the increasement of GO content, but for the same GO content there seems to be no noticeable difference. For Young's modulus presented in Figure 8(b), the noticeable increase trend with the increasement of GO content can be found. As mentioned above, generally the higher the GO content in the cemented loess, the denser the microstructure due to presence of more C-S-H gel, thus resulting in the higher stiffness of the material [27]. Therefore, the deformation capacity like ultimate strain would be degraded, while Young's modulus would be improved.

\subsection{Effect of GO on the Compressive and Flexural Strength.} Figure 9 presents the compressive and flexural strength of $\mathrm{GO} /$ cement/loess composite with different GO content for $7 \mathrm{~d}, 14 \mathrm{~d}$, and $28 \mathrm{~d}$. As indicated, for different ages, both the compressive and flexural strength increased progressively with the increase of GO content. Additionally, compared with the samples without GO, the corresponding compressive strength of $7 \mathrm{~d}, 14 \mathrm{~d}$, and $28 \mathrm{~d}$ showed maximum increasement of about $21.29 \%, 57.97 \%$, and $39.00 \%$, while the corresponding flexural strength of $7 \mathrm{~d}, 14 \mathrm{~d}$, and $28 \mathrm{~d}$ was $33.57 \%, 39.56 \%$, and $28.26 \%$, respectively. Another interesting phenomenon was that the mechanical strength seemed to stop increasing when the GO dosage exceeded 0.09 wt. \%. This may be due to the fact that the dispersion of $\mathrm{GO}$ in the matrix becomes worse as the dosage increases, thus degrading the effect of enhancement just as it does in cement matrix [24].

3.5. Effect of GO on the Water Resistance. Figure 10 shows the water adsorption and softening coefficient changing with GO content from 0 to 0.12 wt. \%. As observed, the water adsorption decreased progressively, while the softening coefficient increased with the increasement of GO content. In more detail, the adsorption deceased by $9.67 \%, 8.82 \%$, $4.09 \%$, and $0.96 \%$, respectively, with the GO content from 0 to $0.12 \%$, while the softening coefficient increased by $5.95 \%$, $4.49 \%, 1.08 \%$, and $0.64 \%$, respectively. Therefore, for both water adsorption and softening coefficient, the extent of reduction decreased gradually with the increasement of GO content and remained almost the same after $0.9 \mathrm{wt}$. \% of GO content, which may be also due to the adverse effect of GO overdosage in the matrix [24].
3.6. Effect of GO Nanosheets on the Microstructure. To study the co-effects of GO and cement on the microstructure of the studied loess, the SEM tests were conducted, as presented in Figure 11. The SEM image of cement/loess without GO (Figure 11(a)) showed a loose microstructure with some voids and straight-through cracks. Additionally, just few hydration products could be observed for the cement/loess sample. Compared with that of cement/loess sample, the SEM image of GO/cement/loess presents a denser microstructure shown in Figures 11(b)-11(f).

Generally, the dispersion in matrix and contact with other particles are two main factors of GO responsible for the enhancement effect. As indicated in Figures 11(b)11(e), the GO sheets were randomly oriented in the matrix. And the agglomerated phenomenon was not detected, illustrating a good dispersion of $\mathrm{GO} /$ cement in the loess matrix. Moreover, according to the SEM results abovementioned, the morphology of GO was thin and wrinkled with a high aspect ratio, which was helpful for a bigger contact area between GO and other particles, thus improving the mechanical properties due to a higher debonding energy. Figure 11(f) showed the interwoven and flower-like structure which had been observed in the GO/ cement composite [24]. The reason was that GO can regulate hydration products to form neat crystal structures, resulting in denser microstructure and higher mechanical properties [21,24].

\section{Discussion}

On the basis of the abovementioned results, the mechanisms of co-effects of GO and cement on the loess matrix can be illustrated as follows.

First of all, the noticeable nucleation effect of GO should be mentioned. As is known, because of the large specific surface, the GO would adsorb the cement and loess particles and become the core of the hydration reaction; that is, particles may tend to concentrate on GO surface. As a result, particles are more likely to react with each other and a denser and interwoven hydrated C-S-H gel structure would become as observed in Figure 11. Thus, it provides a greater possibility for the optimization of microstructure and the improvement of mechanical properties.

Secondly, it should be attributed to the acceleration effect of GO on the hydration process of cement. For the cement/loess system, the enhancement effect is mainly attributed to the higher bonding force generated by C-S-H gel from cement hydration products. So, the more and faster the C-S-H generation, the better the enhancement effect on the loess. Based on the previous research studies [18-26], it had been an agreement that the GO can facilitate the hydration progress of cement due to the amount of active functional oxygen groups $(-\mathrm{OH},-\mathrm{COOH})$ on the $\mathrm{GO}$ surface, thus promoting the generation of $\mathrm{C}-\mathrm{S}-\mathrm{H}$, which is responsible for the improvement of mechanics performance. Therefore, depending on the synergistic effect of GO and cement on loess matrix, more and faster C-S-H gel will be generated, resulting in a denser microstructure and better mechanical properties. 


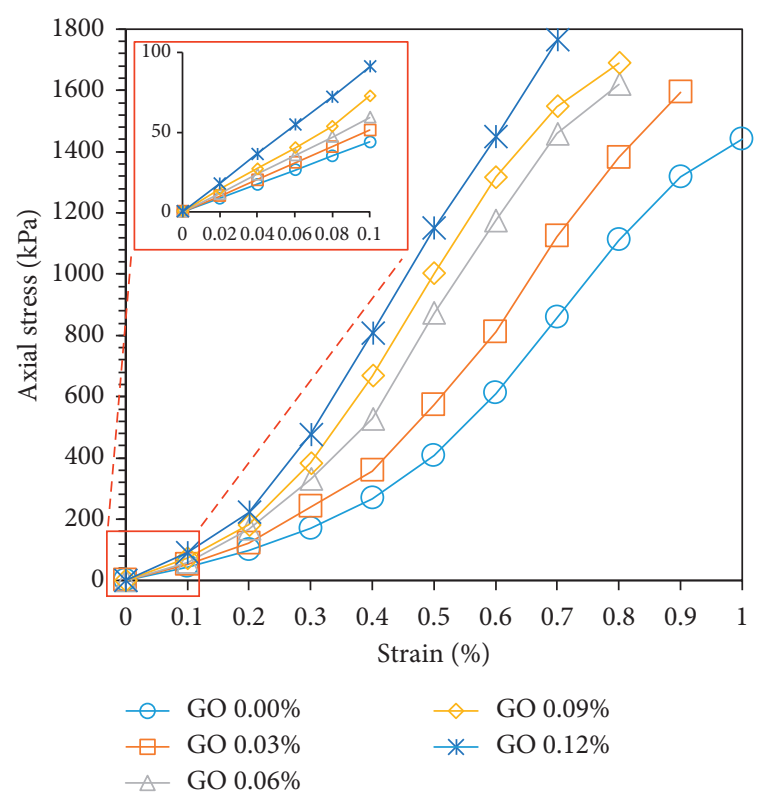

(a)

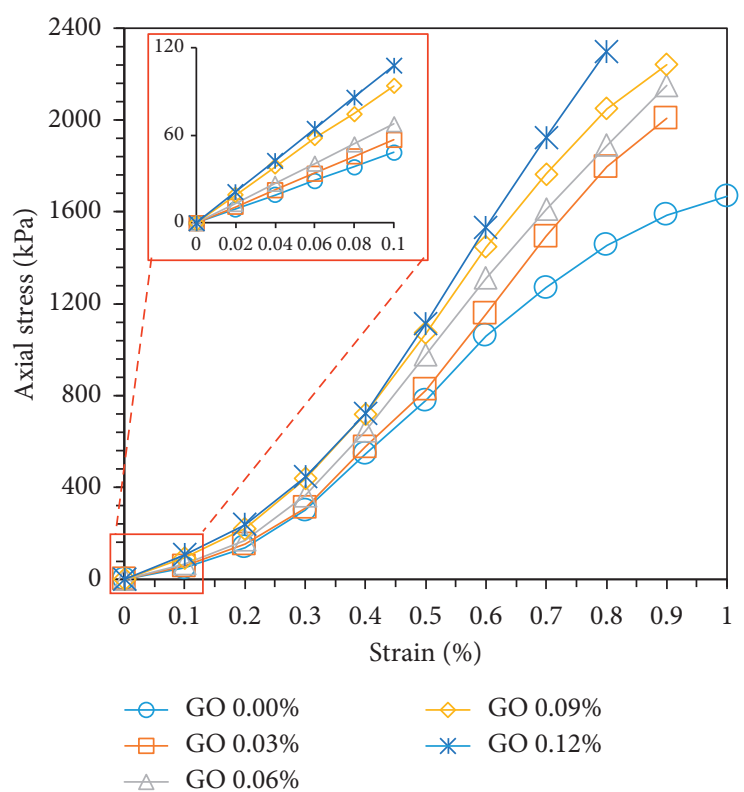

(b)

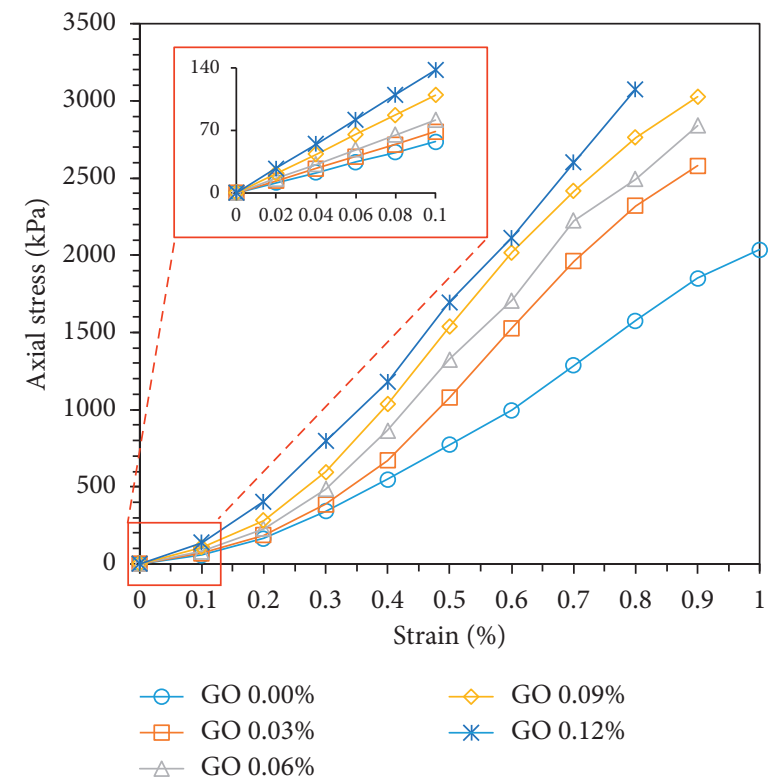

(c)

FIgURE 7: Effect of GO on compressive stress-strain behavior of the loess samples for $7 \mathrm{~d}$ (a), $14 \mathrm{~d}$ (b), and $28 \mathrm{~d}$ (c).

Thirdly, the ion exchange absorption effect is another important mechanism of the synergistic effect of $\mathrm{GO} /$ cement on loess matrix, as presented in Figure 12. As is known, the exchange absorption would occur between ions of $\mathrm{K}^{+}, \mathrm{Na}^{+}$ on the surface of loess particles and the $\mathrm{Ca}^{2+}$ ion generated from the cement hydration. With the addition of these highvalence ions, the double electric layer thickness of loess will become thinner, resulting in higher bonding force between loess particles, thus improving the microstructure and mechanical properties of the composite. Therefore, depending on the facilitating effect of GO on cement hydration, the amount of $\mathrm{Ca}^{2+}$ would be generated, resulting in more broadly and deeply exchange absorption between ions. Then, a better enhancement effect would come into being.

Additionally, the filling and bridging effects are also responsible for the enhancement effect. With the incorporation of GO, the voids between the particles would be filled by the nanosized GO, resulting in improved characteristics of pores. What is more, for the addition of GO, cracks would be effectively refined, bridged, and forced to twist around the GO sheets, as shown in Figure 13, which is similar to the results 


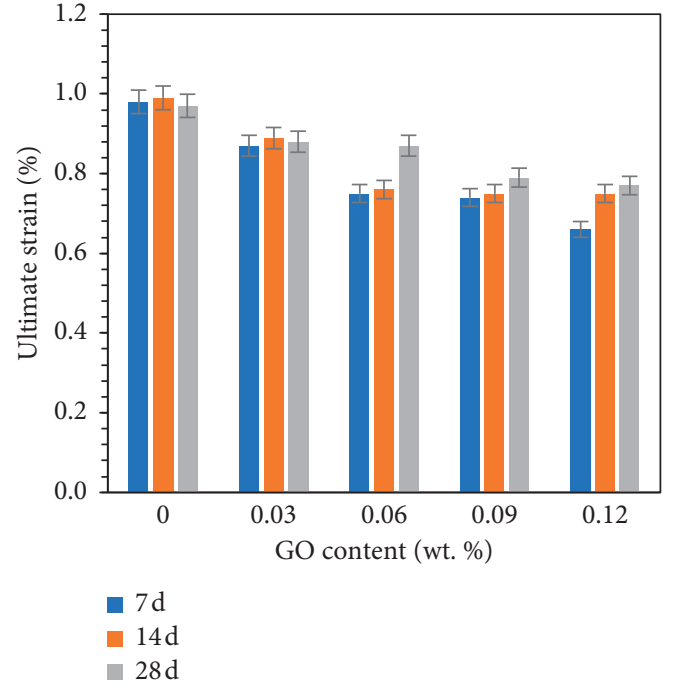

(a)

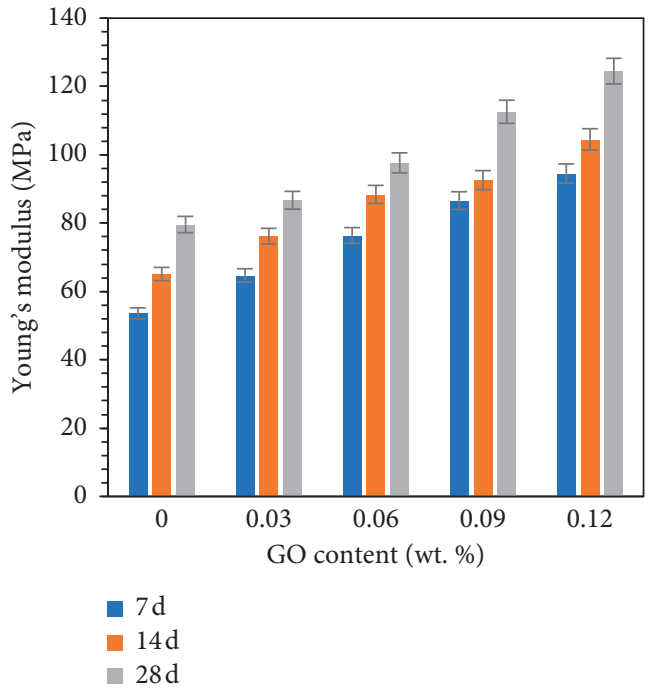

(b)

Figure 8: Ultimate strain and Young's modulus of GO/cement/loess composites with different GO contents: (a) ultimate strain; (b) Young's modulus.

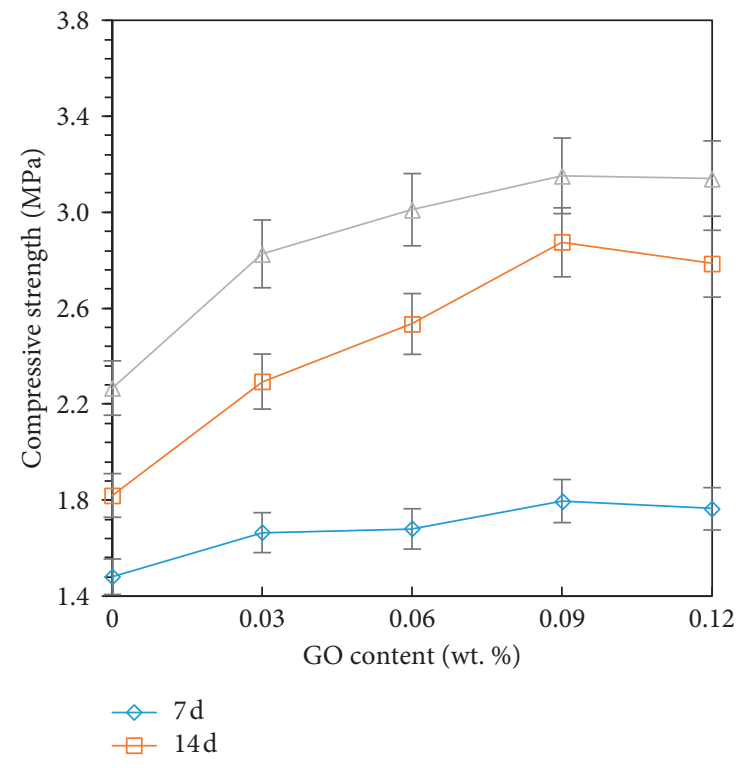

(a)

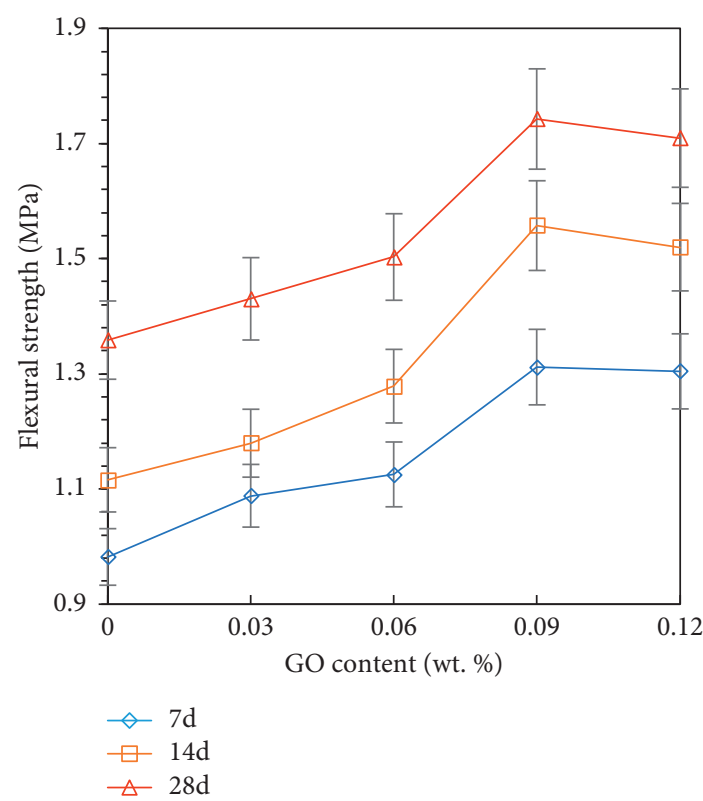

(b)

FIGURE 9: Curves of mechanical properties changing with GO: (a) compressive strength; (b) flexural strength. 


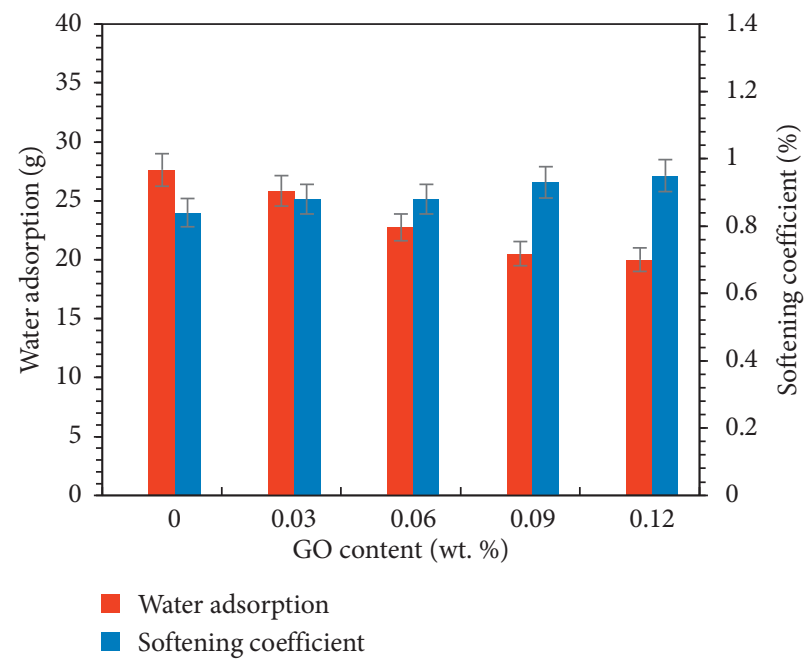

FIGURE 10: Water adsorption and softening coefficient changing with GO content.

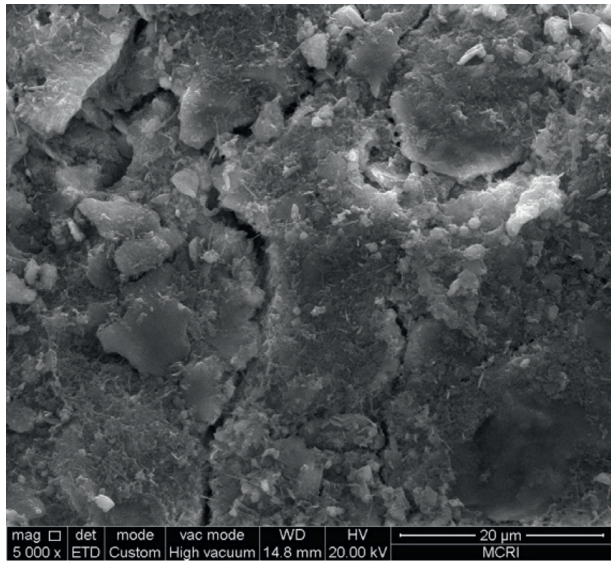

(a)

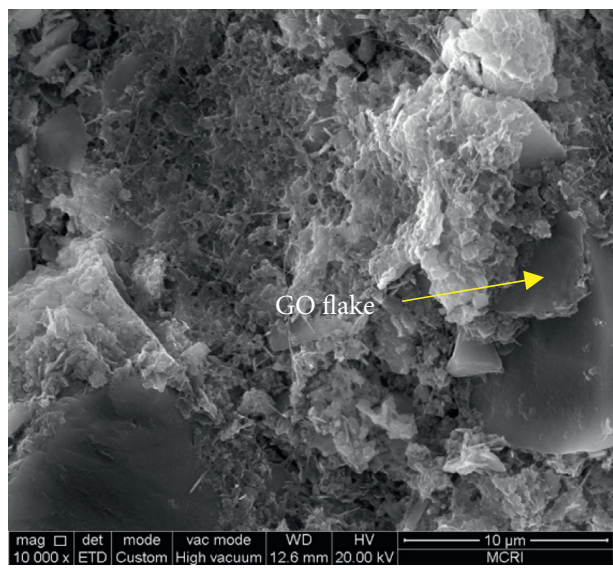

(c)

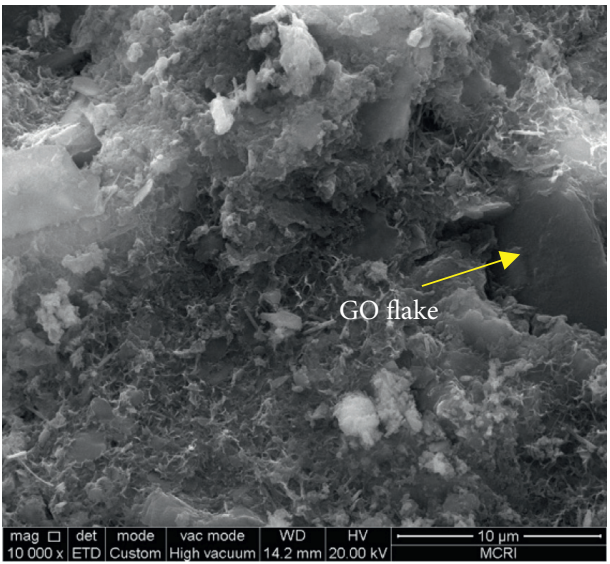

(b)

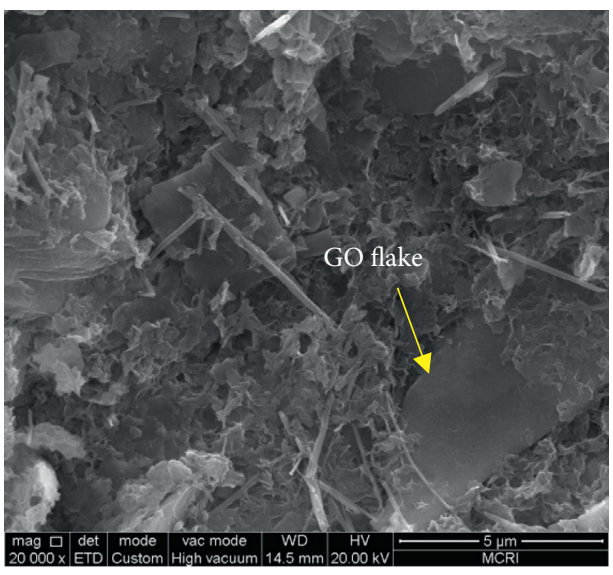

(d)

Figure 11: Continued. 


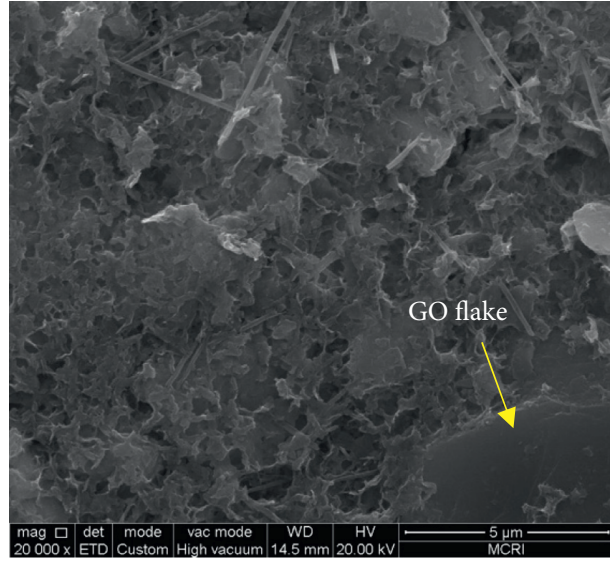

(e)

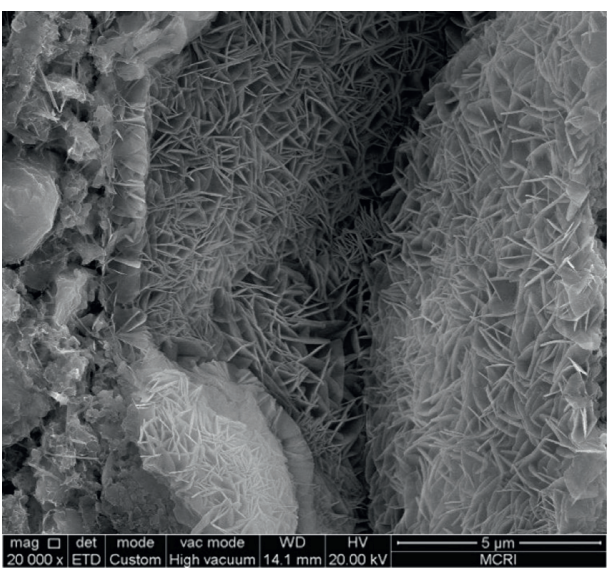

(f)

FIGURE 11: SEM images of structures of cement/loess and GO/cement/loess samples at $28 \mathrm{~d}$ : (a) cement/loess without GO; (b) 0.03\% GO/ cement/loess; (c) $0.06 \% \mathrm{GO} /$ cement/loess; (d) $0.09 \% \mathrm{GO} /$ cement/loess; (e) $0.12 \% \mathrm{GO} /$ cement/loess; (f) interwoven and flower-like structure.

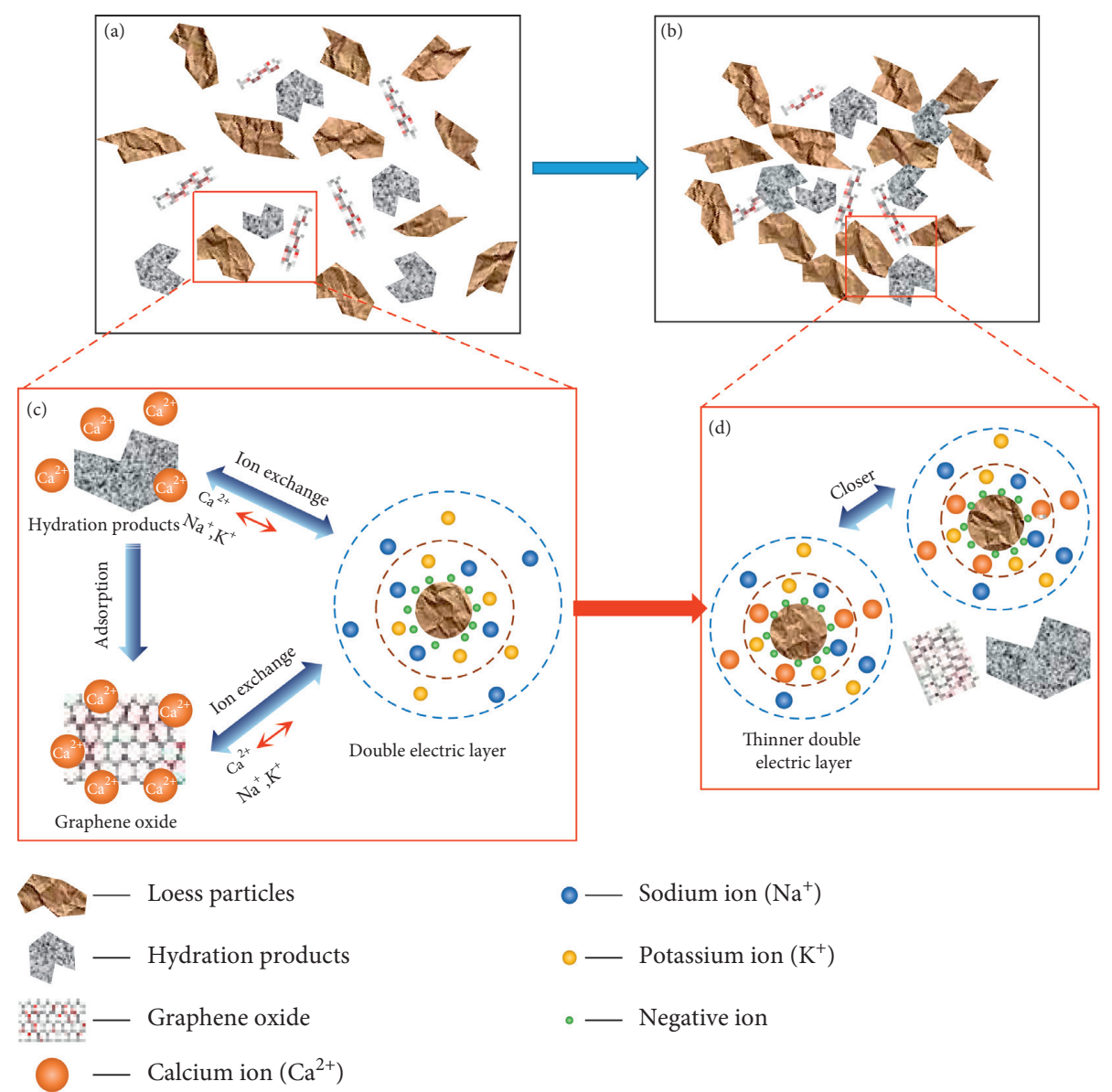

Figure 12: Schematic diagrams of absorption and exchange effect of ions: (a) loose structure before the effect; (b) denser structure after the effect; (c) detail of absorption and exchange effect of ions between GO and cement hydration products and loess particles; (d) thinner double electric layer after absorption and exchange effect of ions, responsible for the denser structure. 


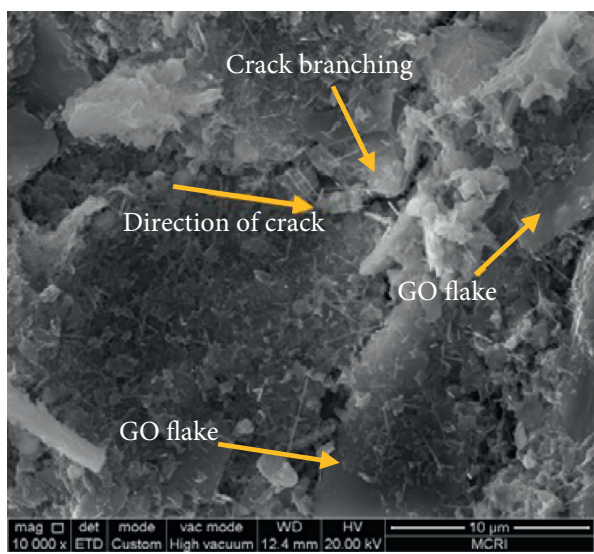

(a)

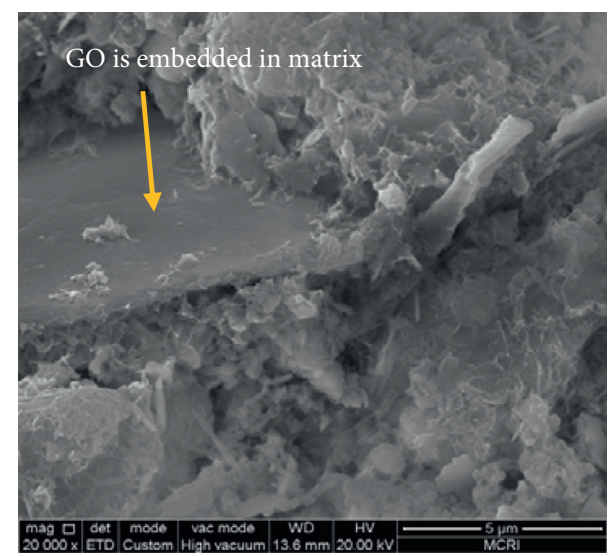

(b)

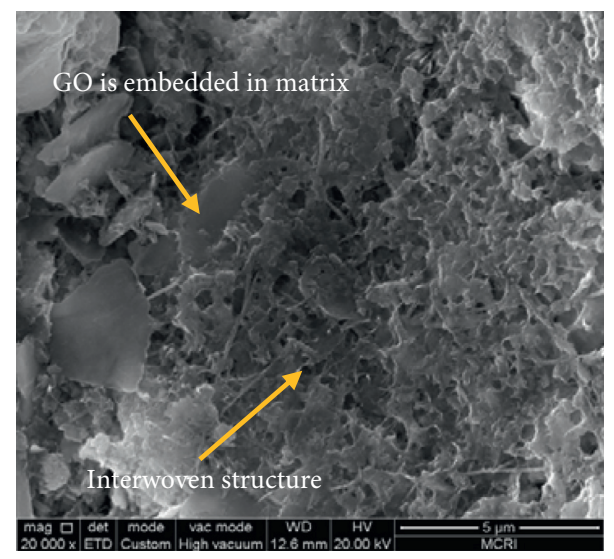

(c)

FIGURE 13: Characteristic toughening mechanism of GO reinforced cemented loess.

concluded by Pan et al. [21] for GO/cement composites. Consequently, depending on the co-effect of GO and cement, a denser and optimum microstructure of $\mathrm{GO} /$ cement/loess composite was generated.

\section{Conclusions}

The reinforced co-effects of GO and cement on loess matrix were assessed from the aspects of compactability, mechanical properties, water resistance, and microstructure. On the basis of the experiments conducted in the present study, several conclusions have been drawn as follows:

(1) The compaction tests revealed that the dry density increased with the increasement of GO incorporation in the cemented loess, while the optimum moisture showed a decreasing trend, which was due to the synergistic effect of GO and cement on loess sample and the microstructure with the presence of $\mathrm{C}-\mathrm{S}-\mathrm{H}$ gel and the interface bonding will be denser.

(2) Both the mechanical properties and water resistance were improved with the increase of GO content. In the present paper, the optimum enhancement effect of mechanical properties and water resistance were detected corresponding to the 0.09 wt. \% GO content.
(3) The SEM results showed that due to the synergistic filling effect and hydration effect of cement/GO, the microstructure was denser and characteristics of crack were refined.

(4) The enhanced mechanism includes both physical and chemical aspects, including nucleation effect, ion exchange adsorption effect, and filling effect, and bridging effect.

\section{Data Availability}

The data are available upon request to the authors.

\section{Conflicts of Interest}

The authors declare that there are no conflicts of interest regarding the publication of this paper.

\section{Acknowledgments}

This research was funded by the National Natural Science Foundation of China (Grants nos. 51878547 and 51641809), China Postdoctoral Fund (Grant no. 2018M633478), the Opening Fund of State Key Laboratory of Green Building in Western China (Grant no. LSKF202010), and Basic Research 
Program of Natural Science in Shaanxi Province (Grant no. 2020JQ-671).

\section{References}

[1] D. Gallipoli, A. W. Bruno, C. Perlot, and J. Mendes, "A geotechnical perspective of raw earth building," Acta Geotechnica, vol. 12, no. 3, pp. 463-478, 2017.

[2] J. C. Morel, J. E. Aubert, Y. Millogo, E. Hamard, and A. Fabbri, "Some observations about the paper "Earth construction: lessons from the past for future eco-efficient construction" by F. Pacheco-Torgal and S. Jalali," Construction and Building Materials, vol. 44, pp. 419-421, 2013.

[3] F. Pacheco-Torgal and S. Jalali, "Earth construction: lessons from the past for future eco-efficient construction," Construction and Building Materials, vol. 29, pp. 512-519, 2012.

[4] T. Ashour, H. Georg, and W. Wu, "An experimental investigation on equilibrium moisture content of earth plaster with natural reinforcement fibres for straw bale buildings," Applied Thermal Engineering, vol. 31, no. 2-3, pp. 293-303, 2011.

[5] M. Bouasker, N. Belayachi, D. Hoxha, and M. Al-Mukhtar, "Physical characterization of natural straw fibers as aggregates for construction materials applications," Materials, vol. 7, no. 4, pp. 3034-3048, 2014.

[6] M. A. Budihardjo, A. Chegenizadeh, and H. Nikraz, "Application of wood to sand-slag and its effect on soil strength," Procedia Engineering, vol. 102, pp. 640-646, 2015.

[7] M. Ghadakpour, A. J. Choobbasti, and S. S. Kutanaei, "Investigation of the Kenaf fiber hybrid length on the properties of the cement-treated sandy soil," Transportation Geotechnics, vol. 22, 2020.

[8] B. V. V. Reddy and P. P. Kumar, "Cement stabilised rammed earth. Part A: compaction characteristics and physical properties of compacted cement stabilised soils," Materials and Structures, vol. 44, no. 3, pp. 681-693, 2011.

[9] S. Liang, J. Chen, M. Guo, D. Feng, L. Liu, and T. Qi, "Utilization of pretreated municipal solid waste incineration fly ash for cement-stabilized soil," Waste Management, vol. 105, pp. 425-432, 2020.

[10] N. Moayyeri, M. Oulapour, and A. Haghighi, "Study of geotechnical properties of a gypsiferous soil treated with lime and silica fume," Geomechanics and Engineering, vol. 17, no. 2, pp. 195-206, 2019.

[11] M. Achenza and L. Fenu, "On earth stabilization with natural polymers for earth masonry construction," Materials and Structures, vol. 39, no. 1, pp. 21-27, 2006.

[12] B. K. G. Theng, "Clay-polymer interactions: summary and perspectives," Clays and Clay Minerals, vol. 30, no. 1, pp. 1-10, 1982.

[13] D. Dermatas and X. Meng, "Utilization of fly ash for stabilization/solidification of heavy metal contaminated soils," Engineering Geology, vol. 70, no. 3-4, pp. 377-394, 2003.

[14] M. Stefanidou and I. Papayianni, "Influence of nano-SiO2 on the Portland cement pastes," Composites Part B: Engineering, vol. 43, no. 6, pp. 2706-2710, 2012.

[15] J. S. Pozo-Antonio and A. Dionísio, "Physical-mechanical properties of mortars with addition of TiO 2 nanoparticles," Construction and Building Materials, vol. 148, pp. 261-272, 2017.

[16] H.-L. Luo, D.-F. Lin, S.-I. Shieh, and Y.-F. You, "Micro-observations of different types of nano-Al2O3on the hydration of cement paste with sludge ash replacement," Environmental Technology, vol. 36, no. 23, pp. 2967-2976, 2015.
[17] J. Makar and G. Chan, "Growth of cement hydration products on single-walled carbon nanotubes," Journal of the American Ceramic Society, vol. 92, 2009.

[18] G. Xu, S. Du, J. He, and X. Shi, "The role of admixed graphene oxide in a cement hydration system," Carbon, vol. 148, pp. 141-150, 2019.

[19] M. Saafi, L. Tang, J. Fung, M. Rahman, and J. Liggat, "Enhanced properties of graphene/fly ash geopolymeric composite cement," Cement and Concrete Research, vol. 67, pp. 292-299, 2015.

[20] E. Horszczaruk, E. Mijowska, R. J. Kalenczuk, M. Aleksandrzak, and S. Mijowska, "Nanocomposite of cement/graphene oxide - impact on hydration kinetics and Young's modulus," Construction and Building Materials, vol. 78, pp. 234-242, 2015.

[21] Z. Pan, L. He, L. Qiu et al., "Mechanical properties and microstructure of a graphene oxide-cement composite," Cement and Concrete Composites, vol. 58, pp. 140-147, 2015.

[22] D.-B. Li, H.-C. Zhang, P.-B. Lei, J.-P. Liu, and D. Zhao, "Synergistic effects of fly ash and graphene oxide on workability, mechanical property of cement-based materials," Science of Advanced Materials, vol. 11, no. 11, pp. 1647-1655, 2019.

[23] Y. Shang, D. Zhang, C. Yang, Y. Liu, and Y. Liu, "Effect of graphene oxide on the rheological properties of cement pastes," Construction and Building Materials, vol. 96, pp. 20-28, 2015.

[24] S. Lv, Y. Ma, C. Qiu, T. Sun, J. Liu, and Q. Zhou, "Effect of graphene oxide nanosheets of microstructure and mechanical properties of cement composites," Construction and Building Materials, vol. 49, pp. 121-127, 2013.

[25] Q. Wang, J. Wang, C.-x. Lu, B.-w. Liu, K. Zhang, and C.-z. Li, "Influence of graphene oxide additions on the microstructure and mechanical strength of cement," New Carbon Materials, vol. 30, no. 4, pp. 349-356, 2015.

[26] F. Babak, H. Abolfazl, R. Alimorad, and G. Parviz, "Preparation and mechanical properties of graphene oxide: cement nanocomposites," The Scientific World Journal, vol. 2014, Article ID 276323, 10 pages, 2014.

[27] F. Naseri, M. Irani, and M. Dehkhodarajabi, "Effect of graphene oxide nanosheets on the geotechnical properties of cemented silty soil," Archives of Civil and Mechanical Engineering, vol. 16, no. 4, pp. 695-701, 2016.

[28] A. J. Choobbasti and S. S. Kutanaei, "Microstructure characteristics of cement-stabilized sandy soil using nanosilica," Journal of Rock Mechanics and Geotechnical Engineering, vol. 9, no. 5, pp. 981-988, 2017.

[29] K. Yao, W. Wang, N. Li, C. Zhang, and L. Wang, "Investigation on strength and microstructure characteristics of nano$\mathrm{MgO}$ admixed with cemented soft soil," Construction and Building Materials, vol. 206, pp. 160-168, 2019.

[30] S. H. Bahmani, B. B. K. Huat, A. Asadi, and N. Farzadnia, "Stabilization of residual soil using $\mathrm{SiO} 2$ nanoparticles and cement," Construction and Building Materials, vol. 64, pp. 350-359, 2014.

[31] D. T. R. Figueiredo, A. A. S. Correia, D. Hunkeler, and M. G. B. V. Rasteiro, "Surfactants for dispersion of carbon nanotubes applied in soil stabilization," Colloids and Surfaces A: Physicochemical and Engineering Aspects, vol. 480, pp. 405-412, 2015. 